OPEN ACCESS

Edited by:

Luman Wang,

Fudan University, China

Reviewed by:

Wataru Ise,

Osaka University, Japan

Elisabetta Traggiai,

Novartis, Switzerland

${ }^{*}$ Correspondence:

Bonnie N. Ditte

bdittel@versiti.org

Specialty section: This article was submitted to B Cell Biology,

a section of the journal

Frontiers in Immunology

Received: 30 September 2021 Accepted: 22 November 2021 Published: 20 December 2021

Citation:

Neu SD and Dittel BN (2021) Characterization of Definitive Regulatory B Cell Subsets

by Cell Surface Phenotype,

Function and Context.

Front. Immunol. 12:787464. doi: 10.3389/fimmu.2021.787464

\section{Characterization of Definitive Regulatory B Cell Subsets by Cell Surface Phenotype, Function and Context}

\author{
Savannah D. Neu ${ }^{1,2}$ and Bonnie N. Dittel ${ }^{1,2 *}$ \\ ${ }^{1}$ Versiti Blood Research Institute, Milwaukee, WI, United States, ${ }^{2}$ Department of Microbiology and Immunology, Medical \\ College of Wisconsin, Milwaukee, WI, United States
}

Regulatory B cell or "Breg" is a broad term that represents the anti-inflammatory activity of $\mathrm{B}$ cells, but does not describe their individual phenotypes, specific mechanisms of regulation or relevant disease contexts. Thus, given the variety of $\mathrm{B}$ cell regulatory mechanisms reported in human disease and their animal models, a more thorough and comprehensive identification strategy is needed for tracking and comparing B cell subsets between research groups and in clinical settings. This review summarizes the discovery process and mechanism of action for well-defined regulatory B cell subsets with an emphasis on the mouse model of multiple sclerosis experimental autoimmune encephalomyelitis. We discuss the importance of conducting thorough B cell phenotyping along with mechanistic studies prior to defining a particular subset of B cells as Breg. Since virtually all B cell subsets can exert regulatory activity, it is timely for their definitive identification across studies.

\begin{abstract}
Keywords: regulatory B cell (Breg cell), IL-10, Treg, autoimmunity, EAE (experimental autoimmune
\end{abstract} encephalomyelitis), multiple scleorsis (MS), $\mathrm{BD}_{\mathrm{L}}$

\section{INTRODUCTION}

Alongside T cells, B cells or B lymphocytes make up the adaptive immune system that recognizes and retains memory of foreign antigen encounters. The B cell receptor (BCR) or immunoglobulin (Ig) is a cell surface protein that recognizes intact antigens. BCR binding to cognate shapes activates $\mathrm{B}$ cells and leads to downstream protective functions including antigen presentation, upregulation of effector cell surface proteins and soluble factors and B cell differentiation into specialized effector subsets $(1,2)$. B cells are continuously produced in the bone marrow (BM) to replenish and replace expended populations in peripheral tissues $(3,4)$. High B cell turnover sustains a large and diverse $\mathrm{BCR}$ repertoire, that can protect against a vast array of foreign antigens, but can also be self-reactive $(3,5,6)$. To minimize pathological autoimmunity regulatory cell subsets, which include $\mathrm{T}$ cells, macrophages and B cells, control and resolve inflammation and reestablish homeostasis through many mechanisms (7-10). Targeting regulatory cells for depletion to boost anti-cancer responses or expansion to dampen autoimmunity is a current therapeutic strategy $(9,11-13)$.

Although there are differences between the human immune system and animal models, B cells have similar functions and residence across species. B cells are divided into two broad subsets based 
on origin. Conventional B2 B cells in mouse and human are BMderived and account for most $\mathrm{B}$ cell populations in circulation and in the secondary lymphoid organs including lymph nodes, spleen and mucosal sites (14). In mice, B1 B cells were shown to be derived from the yolk sac/fetal liver and largely self-renew in the peritoneal cavity and surrounding abdominal tissues and secrete large amounts of IgM for innate-like immune protection $(15,16)$. B1 B cells are subdivided into B1a and B1b in mice (17). Both B2 and B1 B cells can engage in antigen-specific immune responses, secrete protective antibodies and become further specialized based on 1) localization to tissue types/structures and proximity to other cells; 2) BCR affinity for self or foreign ligands and 3) availability of growth signals, stimulation, and differentiation factors. In both mice and humans, BM-derived B cells follow a maturation trajectory from immature states (pre-B, pro- $\mathrm{B}$, transitional) to mature marginal zone and follicular subsets (18). Naïve B1 and B2 B cells become activated through their BCR and related signaling (co-stimulation, cytokines) and differentiate into long-lived memory or antibody secreting plasma cells $(19,20)$. During differentiation into plasma cells, activated B cells in both mice and humans, downregulate canonical B cell markers (CD19, surface Ig, Pax5) and upregulate transcriptional programs needed for efficient protein folding and secretion (IRF4, Blimp-1, XBP1) (19, 2124). In this process, $B$ cells mature through an intermediary plasmablast stage characterized by high proliferation and migration to effector sites $(19,21)$.

While the term "Breg" denotes a unique B cell subset, regulatory activity can be found in virtually all B cell subsets (25-28). Thus, Breg describes the general capacity for B cells to dampen immune responses but does not detail their exact nature, i.e., phenotype, mechanism of regulation or functional context. Many recent reviews summarize a multitude of mechanisms by which B cells are anti-inflammatory. For simplicity, these mechanisms are often divided into IL-10-dependent and -independent activities (10, 26, 28, 29). We support the concept that while all B cell subsets have contextual regulatory capacity, some subsets are inherently better suited than others. Because of this complexity, characterization of specific B cell subsets that exert regulatory activities has been incomplete and inconsistent across model systems and between research groups. Thus, there is a need for a definitive characterization strategy to assess novel regulatory B cell subsets. Here, we will review the history of B cell immune regulation research with focus on the discovery and testing of B cell subsets whose phenotype and mechanism of action have been clearly delineated. These include IL-10 producing plasmablasts/plasma cells (30-32) (Figure 1) and B cell IgD low $\left(\mathrm{BD}_{\mathrm{L}}\right)$ that interact with and induce proliferation of $\mathrm{CD} 4^{+} \mathrm{Foxp} 3^{+}$ $\mathrm{T}$ regulatory cells (Treg) (33) (Figure 2). In each of the four articles highlighted, negative immune regulation was assessed using the animal model of multiple sclerosis (MS), experimental autoimmune encephalomyelitis (EAE), and measured as the level of recovery from the signs of disease. Although $\mathrm{B}$ cell negative immune regulation has been reported in a variety of human disease models, for brevity and continuity, we are limiting this review to MS and its animal model EAE.

\section{THE DISCOVERY OF B CELL NEGATIVE IMMUNE REGULATION}

The discovery of a regulatory role for B cells in autoimmunity, ironically, was a serendipitous finding that was the outcome of a study in the laboratory of Dr. Charles A. Janeway, Jr. to determine whether $\mathrm{B}$ cell antigen presentation of peptides could induce CD4 $\mathrm{T}$ cell priming. This question was asked using EAE, which was well suited to address the question because of its dependence upon $\mathrm{CD} 4 \mathrm{~T}$ cell priming to a selfantigen (34). EAE was induced in B10.PL $\left(\mathrm{H}-2^{\mathrm{u}}\right)$ mice by immunization with the myelin basic protein (MBP) immunodominant peptide $\mathrm{Ac}_{1-11}$ emulsified in complete Freund's adjuvant accompanied by two doses of pertussis toxin (day 1 \& 2) (35). This model was chosen because it was the first peptide active immunization model of EAE (36). To address the original question, B10.PL mice rendered deficient of mature B cells by disruption of the IgM heavy chain (B10.PL $\mu M T$ ) (37) were immunized with $\mathrm{Ac}_{1-11}$ (35). Now as part of scientific history, we showed that $\mu \mathrm{MT}$ mice not only succumbed to EAE, but failed to recover from the signs of EAE (35). This later finding is an advantage of using B10.PL mice because WT mice spontaneously recover from EAE. Although this result did not answer the original question of whether B cells can take up and present peptide antigens to $\mathrm{T}$ cells, it did indicate that $\mathrm{B}$ cell antigen presentation was not required for EAE induction. The observation that the mice did not recover from EAE provided the first evidence that $B$ cells play a regulatory role in autoimmune responses. Remarkably, this finding was obtained prior to the identification of $\mathrm{CD}^{+} \mathrm{Foxp}^{+}$Treg. The question then became, through what mechanisms do $B$ cells facilitate resolution of EAE or other inflammatory conditions?

\section{IL-10/IL-35-SECRETING PLASMABLASTS/ PLASMA CELLS}

IL-10 is a strong anti-inflammatory cytokine, which can potently suppress antigen presentation, among other functions, leading to attenuated immune responses $(38,39)$. IL-10-deficient mice develop a severe, nonrecovery EAE phenotype much like B cell-deficient animals $(40,41)$. Fillatreau and colleagues, in 2002, reproduced our findings that B cells are required for EAE recovery in $\mathrm{C} 567 \mathrm{BL} / 6$ mice using the myelin oligodendrocyte glycoprotein (MOG) 35-55 peptide immunization model (42). Mechanistically, they were the first to demonstrate a role for B cell production of IL-10 in EAE recovery (42). This was accomplished utilizing IL-10-deficient mice and a combination of mixed BM chimeras and B cell transfers. Since this landmark finding, a multitude of subsequent studies have assessed B cell production of IL-10 through methods such as ELISA and ELISPOT, flow cytometry, fluorescent reporters and quantitative PCR (43). IL-10 production was commonly assessed following potent antigen non-specific in vitro B cell stimulation (44). While many, if not all, B cell 


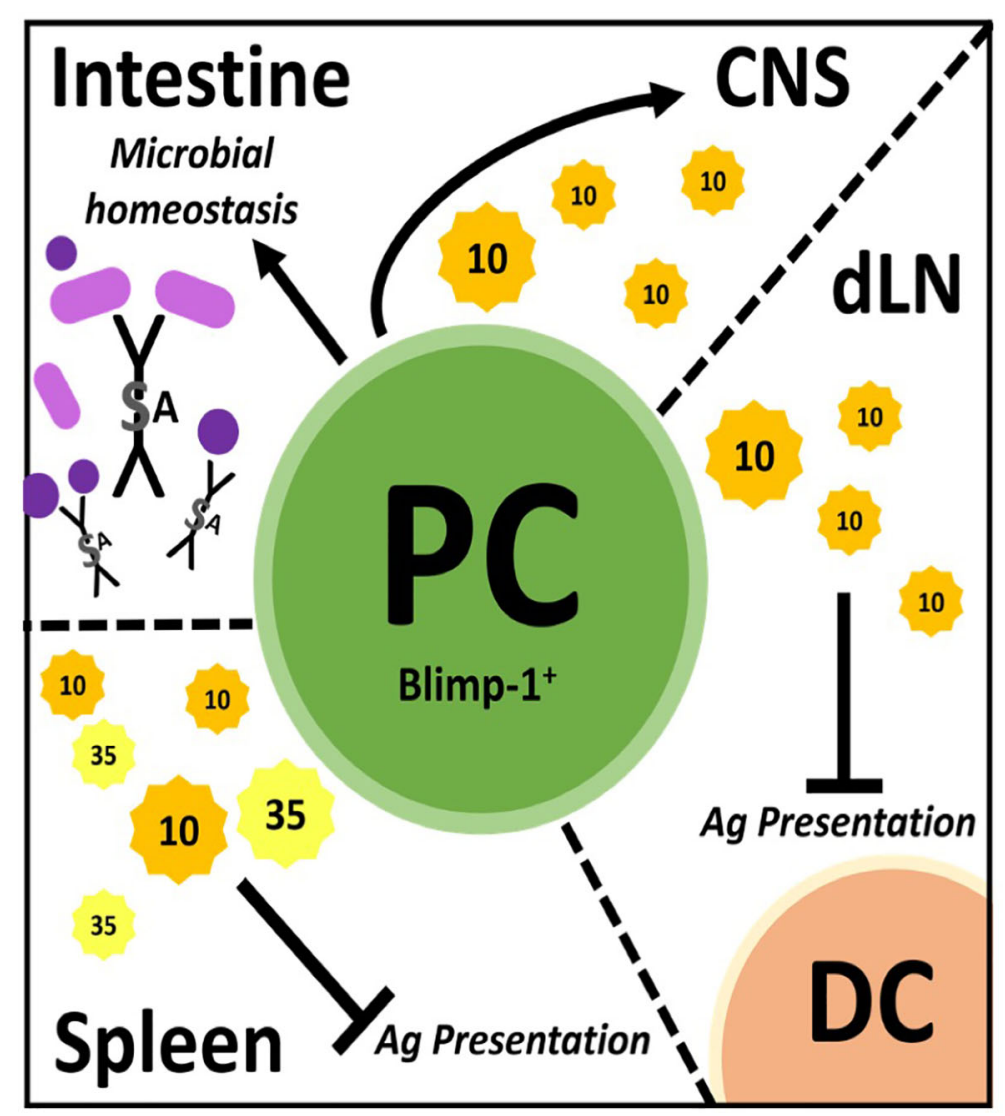

FIGURE 1 | Plasmablast/plasma cells (PC) regulate through many mechanisms in different tissues. PC facilitate microbial homeostasis at mucosal surfaces like the small and large intestine through secretion of IgA, a dimerized lg with added features. These PC can migrate to the central nervous system (CNS) and secrete IL-10 to dampen inflammation therein. In draining lymph nodes (dLN), PC secrete IL-10 to inhibit antigen (Ag) presentation by dendritic cells (DC), thereby dampening immune responses. PC secrete IL-10 and IL-35 in the spleen which is believed to inhibit Ag presentation therein.

subsets can produce IL-10 after in vitro stimulation, concurrent secretion of pro-inflammatory cytokines (IL-6, TNF- $\alpha$ ) has been reported, suggesting that in vitro activation is not sufficient to assess true regulatory activity via IL-10 $(25,45)$. Indeed, B10 B cells named for their production of IL-10, are not a specific subset of B cells, but defined by IL-10 production, regardless of whether the IL-10 is regulatory in a disease context (28). Thus, measuring IL-10 production alone is not sufficient to define/ phenotype $\mathrm{B}$ cell subsets with regulatory activity. The later requires mechanistic studies utilizing well-defined and/or purified B cell subsets, and as shown by Fillatreau and colleagues (42), the utilization of IL-10-deficient B cells.

Once it was recognized that B cell production of IL-10 was antiinflammatory in EAE, the search commenced to identify the phenotype of the regulatory $\mathrm{B}$ cell. This was a daunting task given that all $B$ cell subsets have the capacity to produce IL-10. In particular, B cells produce copious amounts of IL-10 following TLR stimulation (44, 46-49). Interestingly, CFA used to induce EAE has numerous TLR ligands and B cells stimulated via TLR ligands were shown to suppress $\operatorname{EAE}(44,46)$. It took until 2014 for the identification of plasmablasts/plasma cells as the major source of B cell-derived IL-10 during EAE (30). In the first of two articles, Fillatreau and colleagues, used both EAE and Salmonella infection along with $\mathrm{BM}$ chimeras utilizing knockout (KO) mice, to demonstrate that IL-35 production was also a critical B cellderived anti-inflammatory cytokine (30). IL-35 as a potential B cell regulator was identified via a microarray approach utilizing $\mathrm{B}$ cells expressing IL-10 as detected using IL-10 reporter mice. They went on to show that splenic plasma cells were the major contributors of IL-10 and IL-35. Here, we want to emphasize that thorough cell surface phenotyping $\left(\mathrm{CD} 138^{\mathrm{hi}} \mathrm{TACI}^{+} \mathrm{CXCR} 4^{+} \mathrm{CD} 1 \mathrm{~d}^{\text {int }} \mathrm{Tim} 1^{\text {int }}\right)$ combined with intranuclear detection of the plasma cell transcription factor Blimp were utilized (30). This was the first time a "definitive" B cell phenotype was identified exhibiting regulatory activity via secretion of IL-10/IL-35 (Figure 1). IL-10/IL-35 production was used as the starting point to identify the B cells, not as the endpoint.

In the same year, Matsumoto and colleagues also reported that plasmablasts were the primary producers of IL-10 in EAE (31). IL-10 reporter mice (Venus) were used as the strategy to identify IL-10 producing B cells, which were highly prevalent in the draining lymph nodes, but not in the spleen or spinal cord on 


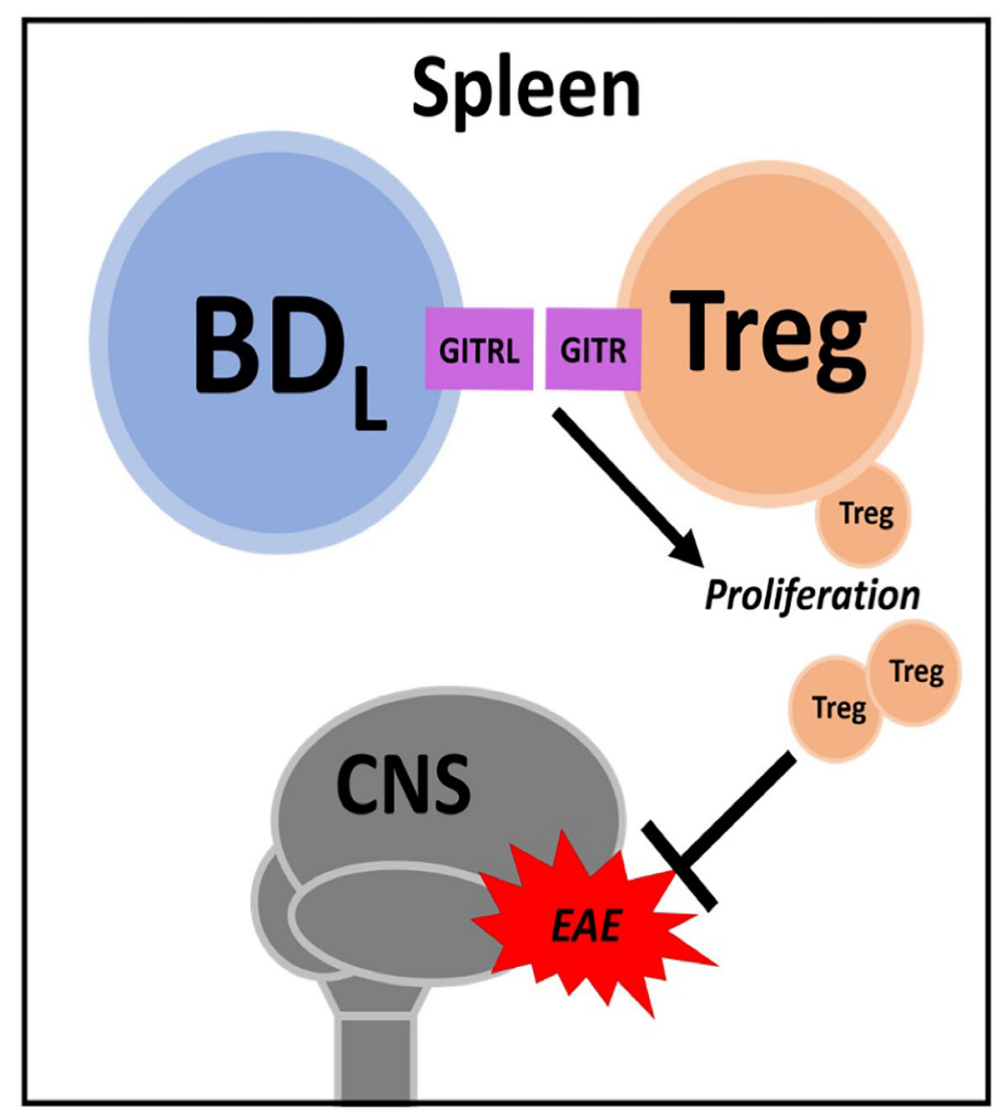

FIGURE 2 | $B D_{L}$. In the spleen $B_{L}$ promote regulatory T cell (Treg) proliferation through GITR-GITRL interactions. Treg attenuate experimental autoimmune encephalomyelitis (EAE) severity.

day 14 of EAE ( peak of disease). Using cell surface phenotyping and intranuclear Blimp-1 staining, $\mathrm{CD}_{138^{+}}$plasmasblasts/ plasma cells were identified as the major IL-10 secreting cells during EAE. Confirmation that the plasmablasts/plasma cells were negative regulatory in EAE came from studies utilizing Blimp-1 B cell conditional KO mice. Additional studies indicated that lymph node, but not splenic plasmablasts/plasma cells were responsible for the negative regulation. To resolve the splenic (30) versus lymph node origin of the regulatory plasmablasts (31), adoptive transfer experiments were conducted, which ultimately demonstrated that the negative immune regulation occured in the lymph node independent of the germinal center (i.e., plasmablasts). In retrospect, the lymph node as the location of B cell-derived IL-10 immune regulation makes intuitive sense, due to IL-10s' potent ability to suppress antigen presentation. $\mathrm{MOG}_{35-55} \mathrm{EAE}$ is induced by immunization driving $\mathrm{T}$ cell priming due to delivery of the peptide to the draining lymph node via dendritic cells. IL-10 has been reported to negatively regulate the upregulation of MHC class II, co-stimulatory molecules and cytokines important for CD4 T cell priming (50, 51). Indeed, in vitro studies suggested that dendritic cells were the target of the plasmablast-derived IL-10 (31). TLR2, 4 and/or
9 agonists in the CFA likely induced the IL-10 production by the plasmablasts/plasma cells $(30,31)$. Here, again, IL-10 production was the starting point and the implementation of multiple strategies were utilized to definitively identify the B cell subset that produced the regulatory IL-10 (Figure 1).

In addition to autoimmunity, $B$ cell activation and differentiation into antibody-secreting plasma cells is also associated with IL-10 competency and immunosuppressive activity in cancer $(31,52-54)$. While plasmablast/plasma cell characterization has narrowed the phenotype for IL-10-secreting B cells, several plasma cell populations exist between the BM, secondary lymphoid organs (spleen/lymph nodes) and mucosal sites (i.e., gut) (55-60). Of importance, not all PC can produce IL-10, such as IgG-secreting plasma cells (53). Interestingly, microbial sensing through TLR (54) and the presence of gut commensals (61) seems required for effective plasmablast/ plasma cell immunosuppression $(30,31)$. The gut microbiome and its role in MS has been investigated using models like germfree, single microbe monocolonized and specific pathogen-free animals in tandem with EAE and by sequencing microbiomes from human patients (62-64). While a definitive MS microbiome is yet unclear, these cumulative studies have 
identified microbes associated with disease activity as well as quiescence and elucidated further mechanisms through which the gut microbiome impacts immune regulation (65-67). While a multitude of mechanisms exist, IgA production in the gut has emerged as an important regulator of the composition of the gut microbiome. IgA is the most abundant Ig in the body. In human adults, around $5 \mathrm{mg}$ is secreted at mucosal surfaces per day (68, 69). IgA is produced by gut plasma cells residing in the lamina propria of the small and large intestine and is secreted as a dimer joined covalently by the J-chain protein which acquires an additional secretory component during translocation into the gut lumen via the epithelium (70-72) (Figure 1). In the gut, IgA canonically targets microbes through antigen-specific binding but can also participate in non-specific binding via glycan-, Jchain-, and secretory component-driven adherence (72-74). Through these combined mechanisms, IgA facilitates clearance of potentially pathogenic microbes while allowing beneficial commensals to thrive $(75,76)$.

Rojas and colleagues, investigated whether there was a link between gut IgA, IL-10 and EAE penetrance (32). They identified gut-derived IgA-secreting plasma cells as a potent source of IL10 and that these cells ameliorated EAE by trafficking from the gut to the brain. In their work, IgA PC were characterized by multiple techniques including fluorescent reporters with parabiosis tracking, flow cytometry and microscopy and were functionally assessed via ELISPOT and adoptive cell transfer analysis. These plasma cells were shown to be IgA- and IL-10secreting, expressed Blimp-1, had low levels of canonical B cell markers (B220) and reacted with gut-derived antigens in vitro

(32) (Figure 1).

While each of the three highlighted studies discussed above were comprehensively and elegantly conducted using state-ofthe-art techniques, one can ask how does induction of EAE with immunization utilizing a potent TLR stimulating adjuvant (CFA) have relevance to human MS? The nature of this question is relevant to most animal models of human disease. Nevertheless, interestingly, all FDA approved therapies for MS have shown efficacy in the EAE model of MS. Although little is known regarding the role of IL-35 in MS, it has been shown to be elevated in the serum of treated patients as compared to the control group (77). A second study found that IL-35 was reduced in relapsing-remitting MS patients as compared to healthy controls (78). A third study reported that IL-35 was higher in MS patients as compared to healthy controls (79). In a fourth study, MS patients infected with helminths had higher levels of IL-35-producing B cells in the CSF, which correlated with reduced MRI lesions, as compared to uninfected patients (80). In vitro studies, showed that IL-35 could drive IL-35 and IL-10 production by $\mathrm{CD}_{1} 9^{+} \mathrm{B}$ cells and induce a Treg-like phenotype (80). While these studies are interesting, the lack of definitive B cell phenotyping limits impact. Taken together, the collective IL35 data indicate that much remains unknown regarding the source of IL-35 in MS and its mechanism of action. Human relevance investigated by Matsumoto and colleagues utilized an in vitro culture system whereby healthy human peripheral blood B cells were stimulated through TLR9 with CpG along with IFN- $\alpha /$ IFN- $\beta$ to induce IL-10 production (31). It was found that of the various plasmablast populations generated, those derived from naïve $\mathrm{B}$ cells, with a $\mathrm{CD} 27^{\text {int }} \mathrm{CD} 38^{+}$phenotype, expressed the highest level of IL-10 and remained $\operatorname{IgM}^{+}$. Whether these cells are regulatory in MS is not known. In the Rojas study, MS patients were utilized to demonstrate that IgA bound bacteria was reduced during active disease (32). The presence of IgAproducing plasma cells in the MS brain has since been confirmed (81). While the gut microbiota is closely associated with IgAsecreting plasma cells, the signals required for IL-10 secretion and migration to sites of autoimmune inflammation require further exploration.

In summary, although plasmablasts/plasma cells identified by Blimp-1 expression were shown to be the regulatory B cell in EAE, each study identified a different mechanism. In the spleen, they regulated via IL-35, via an unknown mechanism (30) (Figure 1). In the lymph node, IL-10 was the primary immunosuppressive cytokine that likely targeted dendritic cell antigen presentation (31) (Figure 1). While in the gut, IgA plasma cells trafficked to the CNS and suppressed via IL-10 (32) (Figure 1). While the IL-10 target in the CNS was not investigated, it was shown that overexpression of IL-10 in the CNS via transfer of immortalized fibroblasts producing IL-10 or an adenovirus expressing IL-10 into the CNS potently attenuated EAE severity $(82,83)$. These collective studies illustrate the complexity of B cell regulation within just the plasmablast/plasma cell subset, which itself is a complex group of cells with differential production of Ig isotypes, anatomical location, cytokine profiles and longevity.

\section{MAINTENANCE OF TREG HOMEOSTASIS BY BD}

As discussed above, we were the first to demonstrate a negative regulatory role for B cells in promoting recovery from EAE (35). This seminal study was conducted using the active immunization model utilizing CFA. To avoid bystander effects of CFA (i.e., TLR agonism), we first confirmed that B10.PL $\mu \mathrm{MT}$ mice did not recover from EAE induced by the passive transfer of $\mathrm{MBP}$ specific encephalitogenic $\mathrm{CD}^{+} \mathrm{T}$ cells generated from MBPTCR transgenic mice $(84,85)$. Interestingly, in this study utilizing BM chimeras, we did investigate IL-10 expression, but in the context of the recently described CD $4^{+}$Foxp $3^{+}$Treg, not $\mathrm{B}$ cells (85). In a follow up study, we utilized anti-CD20 B cell depletion as an alternative to genetic disruption $(\mu \mathrm{MT})$ to render mice B cell deficient, to further support our findings that B cells are required for EAE recovery (86). In this study, we moved from a BM chimera approach to B cell adoptive transfer and showed that neither IL-10 nor MHC class II were required for B cells to drive EAE recovery. Keeping with our previous findings, we investigated a role for Treg and found that B cells induced their proliferation in a glucocorticoid-induced tumor necrosis factor receptor ligand (GITRL)-dependent manner (Figure 2). This mechanism was supported by findings that mice deficient in $\mathrm{B}$ cells (either $\mu \mathrm{MT}$ or anti-CD20 depleted) had a significant reduction in splenic Treg and that $\mathrm{B}$ cell adoptive transfer into 
$\mu \mathrm{MT}$ mice restored Treg numbers and recovery from EAE. Antibody blocking of GITRL prior to B cell adoptive transfer, attenuated Treg expansion and EAE recovery.

By utilizing two different EAE models (active \& passive) and two means to render mice deficient in B cells (genetic \& antibody depletion), we were confident that $\mathrm{B}$ cells were required for recovery from $\operatorname{EAE}(85,86)$. We then required a strategy by which to identify and subsequently purify the regulatory B cell subset. Unlike IL-10, we could not utilize GITRL due to its very low expression on B cells (86). We did perform some targeted adoptive transfers using FACS purified B cell subsets, but found that strategy too laborious, costly and unfocused. Thus, we chose anti-CD20 partial B cell depletion. By swabbing the $\operatorname{IgG}_{2 \mathrm{a}}$ heavy chain of the totally $B$ cell depleting anti-CD20 to $\operatorname{IgG}_{1}$, B cell depletion efficiency was reduced $(33,87)$. We would like to thank Biogen Idec for generously providing these antibodies. AntiCD20 IgG $\mathrm{Ig}_{1}$ depleted the majority of follicular B cells while sparing marginal zone B cells (33). Thus, we were surprised that the $\mathrm{B}$ cell regulatory activity resided within the few follicular B cells that were not depleted (33). We then employed extensive flow cytometry cell surface phenotyping to determine that the non-depleted follicular B cells were enriched for $\operatorname{IgD}^{\text {low }}$ expressing B cells. Using FACS purified follicular $\operatorname{IgD}^{\text {low }} \mathrm{B}$ cells, we showed that upon transfer into $\mu \mathrm{MT}$ mice, they drove Treg proliferation and EAE recovery. Importantly, neither follicular $\operatorname{IgD}^{\text {hi }}$ nor marginal zone $\mathrm{B}$ cells exhibited regulatory activity. Given that only follicular $\operatorname{IgD}^{\text {low }} \mathrm{B}$ cells were regulatory in the context of our EAE model in conjunction with RNAseq studies, this evidence supported that we had identified a new B cell subset and named them $B$ cell $\operatorname{IgD}$ low $\left(\mathrm{BD}_{\mathrm{L}}\right)$. Several strategies were utilized to determine that $\mathrm{BD}_{\mathrm{L}}$ are not part of the marginal zone $\mathrm{B}$ cell lineage. Developmental studies showed that $\mathrm{BD}_{\mathrm{L}}$ emerge in the spleen after the transitional 2 subset, similar to follicular B cells. However, how $\mathrm{BD}_{\mathrm{L}}$ fit into follicular $\mathrm{B}$ cell development is not known. A more comprehensive review of how $\mathrm{BD}_{\mathrm{L}}$ were discovered and the assays used to identify then were recently published $(88,89)$.

We too, were interested in whether our findings were relevant to humans. In that regard, we found that $\mathrm{BD}_{\mathrm{L}}$ activity existed in $\mathrm{IgD}^{\text {low }} \mathrm{B}$ cells in both human spleen and peripheral blood, as determined using an in vitro Treg expansion assay (33). However, a definitive human $\mathrm{BD}_{\mathrm{L}}$ phenotype was not identified nor were studies in MS performed. Thus, much remains to be discovered regarding B cell biology, particularly in the context of disease. In summary, by utilizing a variety of experimental approaches combined with comprehensive cell surface phenotyping and mechanistic studies, like IL-10 secreting plasmablasts/plasma cells, we have successfully identified a definitive B cell subset with regulatory activity $(33,88)$.

\section{B CELL PHENOTYPING TO IDENTIFY REGULATORY B CELL SUBSETS}

Previous research has uncovered many B cell subsets with regulatory potential that utilize a large cadre of regulatory mechanisms $(10,26)$. This highlights the complexity and challenges in targeting these populations for in-depth testing and therapeutic development. Here, we describe a strategy for identifying regulatory $\mathrm{B}$ cell subsets using gold-standard and state-of-the-art methodology that has three steps: 1) in-depth B cell subset phenotyping, 2) determination of B cell subset origin and 3) functional/mechanistic analysis. These steps do not need to be performed in a specific order, and the process of definitively characterizing a novel subset is often iterative and cyclic in nature (Figure 3).

\section{In-Depth B Cell Subset Phenotyping}

For in-depth B cell subset phenotyping, flow cytometry is a powerful tool that allows for comparative analysis of many cell surface and intracellular/intranuclear markers combined. However, conventional flow cytometry is limited in breath due to an upper limit of 12-14 colors (markers) with a conventional flow cytometer equipped with four lasers. If the flow cytometer also has a UV laser, 20 colors are possible. However, realistically, most laboratories have a upper limit of 6-8 colors. In our studies, identification of $\mathrm{BD}_{\mathrm{L}}$ required six colors that includes $\mathrm{B} 220$ or $\mathrm{CD} 19$, IgM, IgD, CD21, CD23 and CD93 (33) (Figure 4). In addition, this combination of cell surface markers can be used to identify splenic transitional subsets, the marginal zone lineage and follicular B cells (Figure 4). In unpublished studies, we have now identified an additional $\mathrm{BD}_{\mathrm{L}}$ marker making our panels seven colors. We also routinely phenotype Treg $\left(\mathrm{CD} 4^{+}\right.$Foxp $\left.4^{+}\right)$and if done in combination with $\mathrm{B}$ cell phenotyping would be nine colors. If $\mathrm{B}$ cells are enzymatically obtained from tissues the hematopoietic marker CD45 along with a live/dead stain need to be included. Determining IL-10 expression requires either a reporter or intracellular staining. Similarly

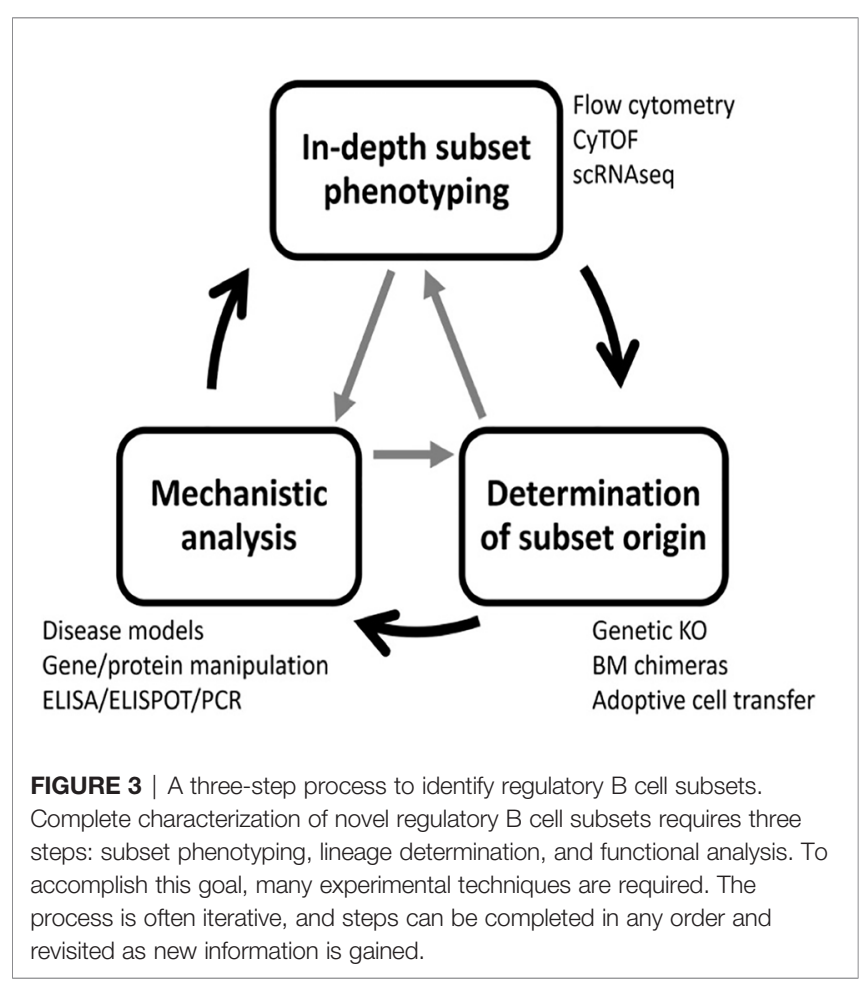




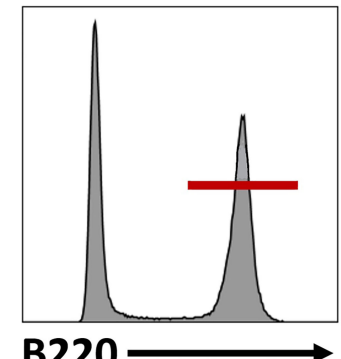

B220
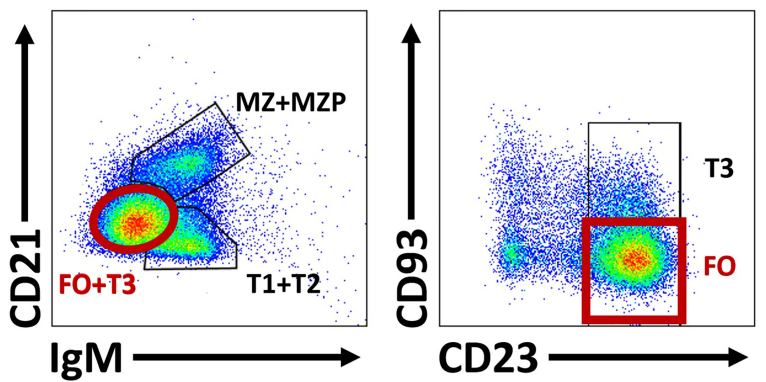

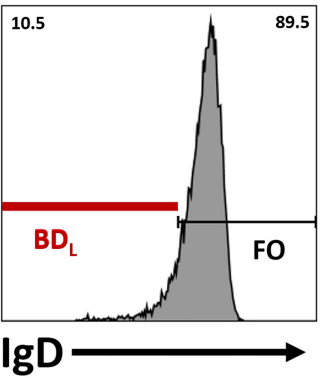

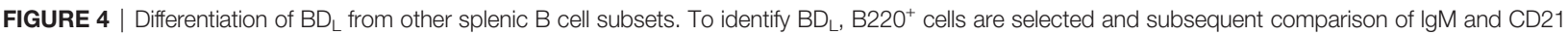
subdivides B cells into three groups based on maturity: marginal zone (MZ) and marginal zone precursors (MZP), transitional 1 (TI) and T2 cell and T3 and follicular (FO) B cells. CD23 and CD93 are subsequently used to identify FO B cells. Within the FO B cell subset, BD $\mathrm{L}_{\mathrm{L}}$ are selected for their low/negative expression of lgD.

complex, delineation between mouse plasmablasts and plasma cells from other B cell subsets requires both cell surface phenotyping, intracellular (IL-10/IL-35) and intranuclear transcription factor identification (i.e., Blimp-1, IRF4), because no cell surface markers alone identify these subsets (Figure 5). Surface markers including $\mathrm{CD} 19^{\text {low/neg }}, \mathrm{B} 220^{\text {low }}, \mathrm{CD} 20^{-}, \mathrm{CD} 38^{+}, \mathrm{CD} 44^{\text {hi }}, \mathrm{CD} 27^{+}, \mathrm{CD} 138^{+}$, $\mathrm{TACI}^{+}, \mathrm{CXCR}^{+}, \mathrm{Tim}^{+}$, cell surface $\mathrm{Ig}^{\text {low/- }}$ are used in addition to transcription factor identification to further characterize subsets of plasmablast/plasma cells (Figure 5). One major hurdle in identifying $\mathrm{BD}_{\mathrm{L}}$ and plasmablasts/plasma cells is that they are rare, making their purification for downstream analysis challenging. Because transcription factor staining for flow cytometry kills target cells, Blimp-1 reporter animals are necessary to FACS purify plasmablasts/plasma cells (90). Additionally, IgMtargeting can activate B cells so care must be taken when purifying cell subsets using this marker. Other markers associated with B cell regulation to consider are CD5, CD1d, PD-L1 and FasL (10, 26). In mouse studies, it is important to analyze several lymphoid tissues to determine if the novel B cell regulatory subsets are sequestered to a portion of the body or more generally found in multiple tissue types.

$\mathrm{B}$ subset markers in mouse and human are relatively similar, but differences do exist. CD10 is a human B cell marker not used in mice and CD38 is used more often in humans than mice (60). Human tissues beyond peripheral blood can be difficult to obtain and B cells in circulation do not allow the analysis of specialized $B$ cells subsets such as marginal zone B cells, germinal center B cells, long-lived plasma cells or mucosal B cell subsets. Human B cell subsets are also infinitely more complex than mice due to exposure to environmental and microorganism-derived antigens leading to isotype class switching and memory and plasma cell generation. Here, $\mathrm{BD}_{\mathrm{L}}$ will be used to illustrate human $\mathrm{B}$ cell complexity. Although, we examined a number of $\mathrm{B}$ cell markers
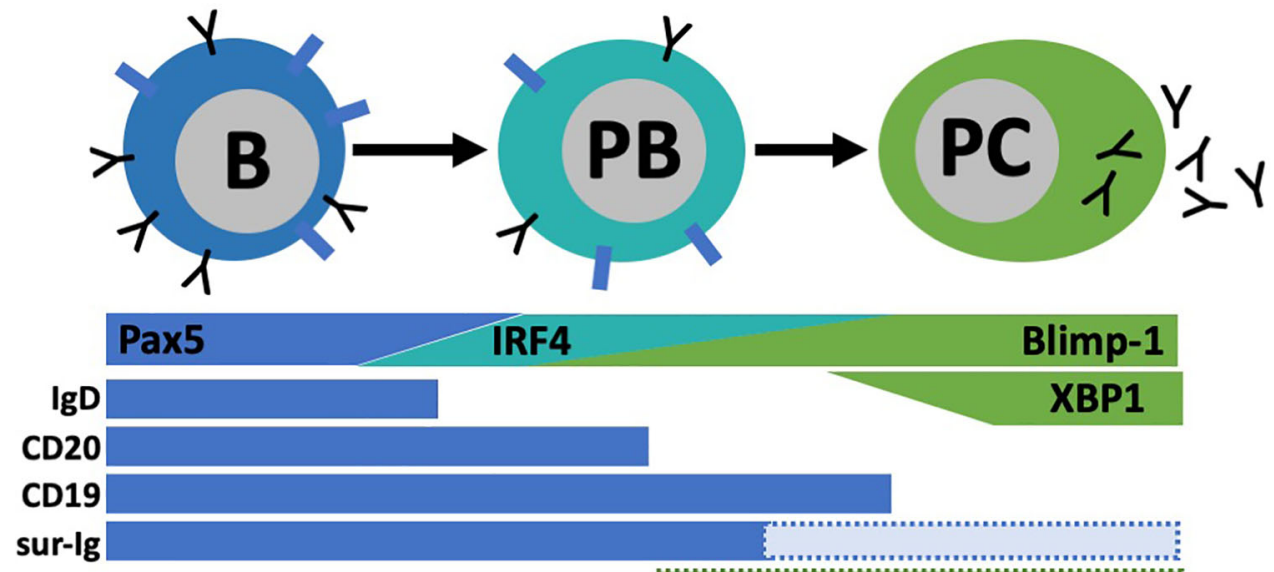

\section{CD138}

FIGURE 5 | Plasmablast (PB)/plasma cell (PC) differentiation. B cells are characterized by their high expression of transcription factor Pax5 and surface markers IgD, CD20, CD19, and surface lg (sur-lg). When B cells differentiate into PC, they transverse through a PB stage known for its high proliferative capacity. As PC maturation continues, Pax5 expression is lost and other transcriptional programs (IRF4, Blimp-I, XBPI) are upregulated. Concurrently, most B cell surface proteins are lost. Some subsets of PB and PC have expression of CD138 among other markers, but not all express these. 
to narrow the $\mathrm{BD}_{\mathrm{L}}$ phenotype in humans (unpublished observations), in the end, the only reliable phenotype was $\mathrm{CD} 9^{+}$(or equivalent $\mathrm{B}$ cell marker) and $\mathrm{IgD}^{\text {low }}$. In addition to $\mathrm{BD}_{\mathrm{L}}$, the $\mathrm{CD} 19^{+} \mathrm{IgD}^{\text {low/- }}$ phenotype can include: 1 ) isotype class switched effector B cells, 2) isotype class switched memory B cells, 3) IgM memory B cells, 4) circulating transitional B cell subsets and 5) circulating marginal zone B cells. It is unlikely that flow cytometry alone could differentiate between the various $\mathrm{IgD}^{\text {low/- }}$ human $\mathrm{B}$ cell subsets. Thus, newer technologies may need to be applied. These include imaging mass cytometry (CyTOF), which is a mass spectrometry approach that utilizes metal conjugated antibodies to identify $\sim 50$ parameters/cells with minimal overlap in the metal signals (91). Primary disadvantages include its lack of mainstream use, slow flow rate and destruction of the analyzed cells. Spectral flow cytometry is a newer technology that also has the advantage of minimal overlap of signals. While similar to conventional flow cytometry, its fluorescent emission spectrum is captured by detectors across several defined wavelength ranges. In essence, every molecule's fluorescent spectrum is recorded as a spectral signature that can be discriminated from other fluorescent signatures (92). Spectral flow cytometers are now commercially available and are slowly being incorporated into basic research studies. Finally, single cell RNA sequencing (scRNAseq) has become a strategy of choice to identify rare subsets of immune cells (93). Detection of cell surface proteins via antibodies (i.e., TotalSeq $^{\mathrm{TM}}$ ) can be used alongside scRNAseq strategies (i.e., 10X Genomices) to analyze the transcriptional profiles of pre-marked immune cell subsets (94). In addition, full-length BCR sequences can also be obtained (95). The best platform to choose is dependent upon the experimental question. 10X Genomics allows the analysis of high numbers of individual cells (thousands) and can be combined with cell surface identification. However, its primary weakness is that sequence read depth is limited to high copy number transcripts, so unique markers expressed at low levels may be washed out during analysis. In comparison, both the Fluidym and Takara systems can analyze sequences with low copy number transcripts, but fewer cells can be analyzed per run (hundreds) $(93,96,97)$.

\section{Determination of B Cell Subset Origin}

$\mathrm{B}$ cell phenotyping can provide strong evidence of the lineage from which a particular B cell subset derives. However, additional developmental studies should be performed. In comparison with conventional B2 B cells from the BM, B1 B cells are derived from the yolk sac/fetal liver, thus they can be eliminated with BM transplantation (98). Marginal zone B cells require Notch-2 signaling for development and any disruption in that pathway prevents their differentiation (99). Plasmablast/plasma cell differentiation can be prevented by loss of Blimp-1 expression (100). The loss of XBP-1 in plasmablasts/plasma cells can be used interrogate relevance of Ig secretion with other mechanisms (101). Germinal center B cells require BCL6 and its deficiency leads to truncation of the germinal center response (102). The transcription factor ABF-1 prevents plasma cells differentiation, without disrupting memory (103). Bach2 was recently shown to be essential for the transition from germinal center B cells to memory B cells (104). Undoubtably, other transcription factors can also be targeted to disrupt the development of specific B cell subsets. The developmental timing/kinetics of any B2 subset can be tracked after BM transplantation or sublethal irradiation (33). In addition, adoptive transfer is also an effective strategy for monitoring B cell subsets, especially when used in tandem with congenic markers (CD45.1/2) (33). For instance, the adoptive transfer of transitional 2 cells leads to the emergence of both the follicular and marginal zone lineages, as well as $\mathrm{BD}_{\mathrm{L}}(33)$. When used together, these $\mathrm{KO}$ and cell reconstitution strategies can experimentally interrogate the lineage of regulatory B cell activity.

\section{Functional/Mechanistic Analysis}

Beyond identifying definitive markers of regulatory B cells subsets and where they come from, characterization of their functional capacity is equally important. Functional capacity includes 1 ) the mechanism through which the regulatory B cell yields an altered immune response and 2) the context in which this is applicable (type of disease, target cells). As evidenced through the story of B cells in EAE, not every regulatory $\mathrm{B}$ cell activity is relevant in all model systems and potentially multiple B cell subsets can be regulatory through different mechanisms at the same time. Thus, choosing and accurately describing the disease context is important for characterizing the regulatory $\mathrm{B}$ cell subset. Mechanisms of regulatory $\mathrm{B}$ cells can be investigated using many of the approaches discussed above where cellular activities (i.e.; IL-10/IL35 secretion) are altered by gene/transcript-targeted deletion/ overexpression or protein inhibition/stimulation with drug compounds. Genetic animal strains (including B cell-conditional varieties), BM chimeras, adoptive cell transfers and in vitro coculture systems are used in tandem with these approaches to minimize confounding effects of gene manipulation on other, non-B cells. Further methods for investigating regulatory B cell mechanisms include measuring cytokines and effector molecule production via reporters (i.e.; IL-10, Blimp-1), ELISA, ELISPOT, quantitative PCR and RNAseq. While conducting these analyses, it is important to keep in mind the purity of tested cell subsets, this is where in-depth B cell phenotyping can aid in and strengthen the interpretation of results.

\section{CONCLUDING REMARKS}

To ensure the accurate identification of novel B cell subsets with regulatory activity and their mechanism, consistent and comprehensive phenotyping along with mechanistic studies are necessary. The four laboratories, including our own, whose work was discussed in this review were chosen because they all utilized multiple strategies to identify a definitive B cell subset whose mechanism of action was confirmed using multiple mechanistic approaches. These included KO mice, BM chimeras, genetic approaches and adoptive cell transfer, among others. Although each story was years in the making, cumulatively, they provide a path by which others can follow to discover novel regulatory B cell subsets and mechanisms in the context of other diseases. Similar investigations have been made in models beyond MS/EAE that researchers interested in B cell regulation should explore. The 
identification of regulatory B cell subsets and their mechanism leads to the question of how they can be exploited for the treatment of anti-inflammatory diseases. The main hurdle with utilizing B cells as an adoptive cell therapy is that they do not selfrenew, like their $\mathrm{T}$ cell counterparts. Thus, longevity must be addressed. In the context of IL-10, adoptive transfer of long-lived plasma cells that produce IL-10 is being actively explored. We are actively exploring how $\mathrm{BD}_{\mathrm{L}}$ can be utilized as an adoptive cell therapy to increase Treg numbers in autoimmunity. These are exciting times for research in $\mathrm{B}$ cell regulation and given the complexity of the entire B cell lineage new B cell subsets and regulatory mechanisms are surely to be discovered.

\section{REFERENCES}

1. Chen Z, Wang JH. How the Signalingcrosstalk of B Cell Receptor (BCR) and Co-Receptors Regulates Antibody Class Switch Recombination: A New Perspective of Checkpoints of BCR Signaling. Front Immunol (2021) 12:663443. doi: 10.3389/fimmu.2021.663443

2. Kwak K, Akkaya M, Pierce SK. B Cell Signaling in Context. Nat Immunol (2019) 20(8):963-9. doi: 10.1038/s41590-019-0427-9

3. Osmond DG. Proliferation Kinetics and the Lifespan of B Cells in Central and Peripheral Lymphoid Organs. Curr Opin Immunol (1991) 3(2):179-85. doi: 10.1016/0952-7915(91)90047-5

4. Tough DF, Sprent J. Lifespan of Lymphocytes. Immunol Res (1995) 14(1):112. doi: $10.1007 / \mathrm{BF} 02918494$

5. H IJ, van Schouwenburg PA, van Zessen D, Pico-Knijnenburg I, Driessen GJ, Stubbs AP, et al. Evaluation of the Antigen-Experienced B-Cell Receptor Repertoire in Healthy Children and Adults. Front Immunol (2016) 7:410. doi: 10.3389/fimmu.2016.00410

6. Bashford-Rogers RJM, Bergamaschi L, McKinney EF, Pombal DC, Mescia F, Lee JC, et al. Analysis of the B Cell Receptor Repertoire in Six ImmuneMediated Diseases. Nature (2019) 574(7776):122-6. doi: 10.1038/s41586019-1595-3

7. Campbell DJ. Control of Regulatory T Cell Migration, Function, and Homeostasis. J Immunol (2015) 195(6):2507-13. doi: 10.4049/ jimmunol.1500801

8. Christoffersson G, von Herrath M. Regulatory Immune Mechanisms Beyond Regulatory T Cells. Trends Immunol (2019) 40(6):482-91. doi: 10.1016/j.it.2019.04.005

9. Gabrilovich DI. Myeloid-Derived Suppressor Cells. Cancer Immunol Res (2017) 5(1):3-8. doi: 10.1158/2326-6066.CIR-16-0297

10. Ray A, Dittel BN. Mechanisms of Regulatory B Cell Function in Autoimmune and Inflammatory Diseases Beyond IL-10. J Clin Med (2017) 6(1). doi: 10.3390/jcm6010012

11. Hofmann K, Clauder AK, Manz RA. Targeting B Cells and Plasma Cells in Autoimmune Diseases. Front Immunol (2018) 9:835. doi: 10.3389/ fimmu.2018.00835

12. Hohlfeld R. B-Cells as Therapeutic Targets in Neuro-Inflammatory Diseases. Clin Immunol (2018) 186:51-3. doi: 10.1016/j.clim.2017.07.013

13. Raffin C, Vo LT, Bluestone JA. Treg Cell-Based Therapies: Challenges and Perspectives. Nat Rev Immunol (2020) 20(3):158-72. doi: 10.1038/s41577019-0232-6

14. Allman D, Pillai S. Peripheral B Cell Subsets. Curr Opin Immunol (2008) 20 (2):149-57. doi: 10.1016/j.coi.2008.03.014

15. Hardy RR, Hayakawa K. Perspectives on Fetal Derived CD5+ B1 B Cells. Eur J Immunol (2015) 45(11):2978-84. doi: 10.1002/eji.201445146

16. Baumgarth N. B-1 Cell Heterogeneity and the Regulation of Natural and Antigen-Induced IgM Production. Front Immunol (2016) 7:324. doi: 10.3389/fimmu.2016.00324

17. Yoshimoto M. The Ontogeny of Murine B-1a Cells. Int J Hematol (2020) 111 (5):622-7. doi: 10.1007/s12185-019-02787-8

18. Wang Y, Liu J, Burrows PD, Wang JY. B Cell Development and Maturation. Adv Exp Med Biol (2020) 1254:1-22. doi: 10.1007/978-981-15-3532-1_1

\section{AUTHOR CONTRIBUTIONS}

$\mathrm{BD}$ and SN both wrote and edited the article. All authors contributed to the article and approved the submitted version.

\section{FUNDING}

This work was supported by the NIH grants R01AI160244-01 and R21AI145323 (BND), the National Multiple Sclerosis Society grant RG-1901-33315 (BD) and the Versiti Blood Research Institute Research Foundation.

19. Fairfax KA, Kallies A, Nutt SL, Tarlinton DM. Plasma Cell Development: From B-Cell Subsets to Long-Term Survival Niches. Semin Immunol (2008) 20(1):49-58. doi: 10.1016/j.smim.2007.12.002

20. Akkaya M, Kwak K, Pierce SK. B Cell Memory: Building Two Walls of Protection Against Pathogens. Nat Rev Immunol (2020) 20(4):229-38. doi: 10.1038/s41577-019-0244-2

21. Nutt SL, Hodgkin PD, Tarlinton DM, Corcoran LM. The Generation of Antibody-Secreting Plasma Cells. Nat Rev Immunol (2015) 15(3):160-71. doi: 10.1038/nri3795

22. Minnich M, Tagoh H, Bonelt P, Axelsson E, Fischer M, Cebolla B, et al. Multifunctional Role of the Transcription Factor Blimp-1 in Coordinating Plasma Cell Differentiation. Nat Immunol (2016) 17(3):331-43. doi: 10.1038/ni.3349

23. Klein U, Casola S, Cattoretti G, Shen Q, Lia M, Mo T, et al. Transcription Factor IRF4 Controls Plasma Cell Differentiation and Class-Switch Recombination. Nat Immunol (2006) 7(7):773-82. doi: 10.1038/ni1357

24. Reimold AM, Iwakoshi NN, Manis J, Vallabhajosyula P, Szomolanyi-Tsuda E, Gravallese EM, et al. Plasma Cell Differentiation Requires the Transcription Factor XBP-1. Nature (2001) 412(6844):300-7. doi: 10.1038/35085509

25. Lighaam LC, Unger PA, Vredevoogd DW, Verhoeven D, Vermeulen E, Turksma AW, et al. In Vitro-Induced Human IL-10(+) B Cells Do Not Show a Subset-Defining Marker Signature and Plastically Co-Express IL-10 With Pro-Inflammatory Cytokines. Front Immunol (2018) 9:1913. doi: 10.3389/ fimmu.2018.01913

26. Ray A, Wang L, Dittel BN. IL-10-Independent Regulatory B-Cell Subsets and Mechanisms of Action. Int Immunol (2015) 27(10):531-6. doi: 10.1093/ intimm/dxv033

27. Rosser EC, Mauri C. Regulatory B Cells: Origin, Phenotype, and Function. Immunity (2015) 42(4):607-12. doi: 10.1016/j.immuni.2015.04.005

28. Tedder TF. B10 Cells: A Functionally Defined Regulatory B Cell Subset. J Immunol (2015) 194(4):1395-401. doi: 10.4049/jimmunol.1401329

29. Cerqueira C, Manfroi B, Fillatreau S. IL-10-Producing Regulatory B Cells and Plasmocytes: Molecular Mechanisms and Disease Relevance. Semin Immunol (2019) 44:101323. doi: 10.1016/j.smim.2019.101323

30. Shen P, Roch T, Lampropoulou V, O'Connor RA, Stervbo U, Hilgenberg E, et al. IL-35-Producing B Cells Are Critical Regulators of Immunity During Autoimmune and Infectious Diseases. Nature (2014) 507(7492):366-70. doi: $10.1038 /$ nature12979

31. Matsumoto M, Baba A, Yokota T, Nishikawa H, Ohkawa Y, Kayama H, et al. Interleukin-10-Producing Plasmablasts Exert Regulatory Function in Autoimmune Inflammation. Immunity (2014) 41(6):1040-51. doi: 10.1016/j.immuni.2014.10.016

32. Rojas OL, Probstel AK, Porfilio EA, Wang AA, Charabati M, Sun T, et al. Recirculating Intestinal IgA-Producing Cells Regulate Neuroinflammation via IL-10. Cell (2019) 176(3):610-624 e18. doi: 10.1016/j.cell.2018.11.035

33. Ray A, Khalil MI, Pulakanti KL, Burns RT, Gurski CJ, Basu S, et al. Mature IgD (low/-) B Cells Maintain Tolerance by Promoting Regulatory T Cell Homeostasis. Nat Commun (2019) 10(1):190. doi: 10.1038/s41467-018-08122-9

34. Croxford AL, Kurschus FC, Waisman A. Mouse Models for Multiple Sclerosis: Historical Facts and Future Implications. Biochim Biophys Acta (2011) 1812(2):177-83. doi: 10.1016/j.bbadis.2010.06.010 
35. Wolf SD, Dittel BN, Hardardottir F, Janeway CA Jr. Experimental Autoimmune Encephalomyelitis Induction in Genetically B Cell-Deficient Mice. J Exp Med (1996) 184(6):2271-8. doi: 10.1084/jem.184.6.2271

36. Zamvil SS, Mitchell DJ, Moore AC, Kitamura K, Steinman L, Rothbard JB. T-Cell Epitope of the Autoantigen Myelin Basic Protein That Induces Encephalomyelitis. Nature (1986) 324(6094):258-60. doi: 10.1038/324258a0

37. Kitamura D, Roes J, Kuhn R, Rajewsky K. A B Cell-Deficient Mouse by Targeted Disruption of the Membrane Exon of the Immunoglobulin $\mathrm{Mu}$ Chain Gene. Nature (1991) 350(6317):423-6. doi: 10.1038/350423a0

38. Moore KW, de Waal Malefyt R, Coffman RL, O'Garra A. Interleukin-10 and the Interleukin-10 Receptor. Annu Rev Immunol (2001) 19:683-765. doi: 10.1146/annurev.immunol.19.1.683

39. Ouyang W, O'Garra A. IL-10 Family Cytokines IL-10 and IL-22: From Basic Science to Clinical Translation. Immunity (2019) 50(4):871-91. doi: 10.1016/ j.immuni.2019.03.020

40. Bettelli E, Das MP, Howard ED, Weiner HL, Sobel RA, Kuchroo VK. IL-10 is Critical in the Regulation of Autoimmune Encephalomyelitis as Demonstrated by Studies of IL-10- and IL-4-Deficient and Transgenic Mice. J Immunol (1998) 161(7):3299-306. doi: 10.1016/S0165-5728(98)91500-4

41. Samoilova EB, Horton JL, Chen Y. Acceleration of Experimental Autoimmune Encephalomyelitis in Interleukin-10-Deficient Mice: Roles of Interleukin-10 in Disease Progression and Recovery. Cell Immunol (1998) 188(2):118-24. doi: 10.1006/cimm.1998.1365

42. Fillatreau S, Sweenie CH, McGeachy MJ, Gray D, Anderton SM. B Cells Regulate Autoimmunity by Provision of IL-10. Nat Immunol (2002) 3 (10):944-50. doi: 10.1038/ni833

43. Methods in Molecular Biology. (Regulatory B Cells: Methods and Protocols) Methods and Protocols. Humana Press. Springer Science+Business Media, LLC, part of Springer Nature (2021),

44. Yanaba K, Bouaziz JD, Matsushita T, Tsubata T, Tedder TF. The Development and Function of Regulatory B Cells Expressing IL-10 (B10 Cells) Requires Antigen Receptor Diversity and TLR Signals. J Immunol (2009) 182(12):7459-72. doi: 10.4049/jimmunol.0900270

45. Langkjaer A, Kristensen B, Hansen BE, Schultz H, Hegedus L, Nielsen CH. B-Cell Exposure to Self-Antigen Induces IL-10 Producing B Cells as Well as IL-6- and TNF-Alpha-Producing B-Cell Subsets in Healthy Humans. Clin Immunol (2012) 145(1):1-10. doi: 10.1016/j.clim.2012.07.004

46. Lampropoulou V, Hoehlig K, Roch T, Neves P, Calderon Gomez E, Sweenie $\mathrm{CH}$, et al. TLR-Activated B Cells Suppress T Cell-Mediated Autoimmunity. J Immunol (2008) 180(7):4763-73. doi: 10.4049/jimmunol.180.7.4763

47. Barr TA, Brown S, Ryan G, Zhao J, Gray D. TLR-Mediated Stimulation of APC: Distinct Cytokine Responses of B Cells and Dendritic Cells. Eur J Immunol (2007) 37(11):3040-53. doi: 10.1002/eji.200636483

48. Bouaziz JD, Calbo S, Maho-Vaillant M, Saussine A, Bagot M, Bensussan A, et al. IL-10 Produced by Activated Human B Cells Regulates CD4(+) T-Cell Activation In Vitro. Eur J Immunol (2010) 40(10):2686-91. doi: 10.1002/ eji.201040673

49. Liu BS, Cao Y, Huizinga TW, Hafler DA, Toes RE. TLR-Mediated STAT3 and ERK Activation Controls IL-10 Secretion by Human B Cells. Eur J Immunol (2014) 44(7):2121-9. doi: 10.1002/eji.201344341

50. Mittal SK, Roche PA. Suppression of Antigen Presentation by IL-10. Curr Opin Immunol (2015) 34:22-7. doi: 10.1016/j.coi.2014.12.009

51. de Waal Malefyt R, Haanen J, Spits H, Roncarolo MG, te Velde A, Figdor C, et al. Interleukin 10 (IL-10) and Viral IL-10 Strongly Reduce AntigenSpecific Human T Cell Proliferation by Diminishing the Antigen-Presenting Capacity of Monocytes via Downregulation of Class II Major Histocompatibility Complex Expression. J Exp Med (1991) 174(4):915-24. doi: 10.1084/jem.174.4.915

52. Shalapour S, Font-Burgada J, Di Caro G, Zhong Z, Sanchez-Lopez E, Dhar $\mathrm{D}$, et al. Immunosuppressive Plasma Cells Impede T-Cell-Dependent Immunogenic Chemotherapy. Nature (2015) 521(7550):94-8. doi: 10.1038/nature14395

53. Suzuki-Yamazaki N, Yanobu-Takanashi R, Okamura T, Takaki S. IL-10 Production in Murine IgM(+) CD138(hi) Cells Is Driven by Blimp-1 and Downregulated in Class-Switched Cells. Eur J Immunol (2017) 47(3):493503. doi: $10.1002 /$ eji.201646549

54. Lino AC, Dang VD, Lampropoulou V, Welle A, Joedicke J, Pohar J, et al. LAG-3 Inhibitory Receptor Expression Identifies Immunosuppressive
Natural Regulatory Plasma Cells. Immunity (2018) 49(1):120-33.e9. doi: 10.1016/j.immuni.2018.06.007

55. Oracki SA, Walker JA, Hibbs ML, Corcoran LM, Tarlinton DM. Plasma Cell Development and Survival. Immunol Rev (2010) 237(1):140-59. doi: 10.1111/j.1600-065X.2010.00940.x

56. Magri G, Comerma L, Pybus M, Sintes J, Llige D, Segura-Garzon D, et al. Human Secretory IgM Emerges From Plasma Cells Clonally Related to Gut Memory B Cells and Targets Highly Diverse Commensals. Immunity (2017) 47(1):118-134 e8. doi: 10.1016/j.immuni.2017.06.013

57. Fitzpatrick Z, Frazer G, Ferro A, Clare S, Bouladoux N, Ferdinand J, et al. Gut-Educated IgA Plasma Cells Defend the Meningeal Venous Sinuses. Nature (2020) 587(7834):472-6. doi: 10.1038/s41586-020-2886-4

58. O'Connor BP, Cascalho M, Noelle RJ. Short-Lived and Long-Lived Bone Marrow Plasma Cells are Derived From a Novel Precursor Population. J Exp Med (2002) 195(6):737-45. doi: 10.1084/jem.20011626

59. Han S, Yang K, Ozen Z, Peng W, Marinova E, Kelsoe G, et al. Enhanced Differentiation of Splenic Plasma Cells But Diminished Long-Lived HighAffinity Bone Marrow Plasma Cells in Aged Mice. J Immunol (2003) 170 (3):1267-73. doi: 10.4049/jimmunol.170.3.1267

60. Brynjolfsson SF, Persson Berg L, Olsen Ekerhult T, Rimkute I, Wick MJ, Martensson IL, et al. Long-Lived Plasma Cells in Mice and Men. Front Immunol (2018) 9:2673. doi: 10.3389/fimmu.2018.02673

61. Rosser EC, Oleinika K, Tonon S, Doyle R, Bosma A, Carter NA, et al. Regulatory B Cells are Induced by Gut Microbiota-Driven Interleukin-1beta and Interleukin-6 Production. Nat Med (2014) 20(11):1334-9. doi: 10.1038/nm.3680

62. Berer K, Mues M, Koutrolos M, Rasbi ZA, Boziki M, Johner C, et al. Commensal Microbiota and Myelin Autoantigen Cooperate to Trigger Autoimmune Demyelination. Nature (2011) 479(7374):538-41. doi: $10.1038 /$ nature 10554

63. Berer K, Gerdes LA, Cekanaviciute E, Jia X, Xiao L, Xia Z, et al. Gut Microbiota From Multiple Sclerosis Patients Enables Spontaneous Autoimmune Encephalomyelitis in Mice. Proc Natl Acad Sci USA (2017) 114(40):10719-24. doi: 10.1073/pnas.1711233114

64. Chen J, Chia N, Kalari KR, Yao JZ, Novotna M, Paz Soldan MM, et al. Multiple Sclerosis Patients Have a Distinct Gut Microbiota Compared to Healthy Controls. Sci Rep (2016) 6:28484. doi: 10.1038/srep28484

65. Cekanaviciute E, Yoo BB, Runia TF, Debelius JW, Singh S, Nelson CA, et al. Gut Bacteria From Multiple Sclerosis Patients Modulate Human T Cells and Exacerbate Symptoms in Mouse Models. Proc Natl Acad Sci USA (2017) 114 (40):10713-8. doi: 10.1073/pnas.1711235114

66. Jangi S, Gandhi R, Cox LM, Li N, von Glehn F, Yan R, et al. Alterations of the Human Gut Microbiome in Multiple Sclerosis. Nat Commun (2016) 7:12015. doi: $10.1038 /$ ncomms 12015

67. Mangalam A, Shahi SK, Luckey D, Karau M, Marietta E, Luo N, et al. Human Gut-Derived Commensal Bacteria Suppress CNS Inflammatory and Demyelinating Disease. Cell Rep (2017) 20(6):1269-77. doi: 10.1016/ j.celrep.2017.07.031

68. Hanson LA, Brandtzaeg P. The Discovery of Secretory IgA and the Mucosal Immune System. Immunol Today (1993) 14(8):416-7. doi: 10.1016/01675699(93)90146-C

69. Chodirker WB, Tomasi TB Jr. Gamma-Globulins: Quantitative Relationships in Human Serum and Nonvascular Fluids. Science (1963) 142(3595):1080-1. doi: 10.1126/science.142.3595.1080

70. Dunn-Walters DK, Isaacson PG, Spencer J. Sequence Analysis of Human IgVH Genes Indicates That Ileal Lamina Propria Plasma Cells Are Derived From Peyer's Patches. Eur J Immunol (1997) 27(2):463-7. doi: 10.1002/eji.1830270217

71. Fagarasan S, Kinoshita K, Muramatsu M, Ikuta K, Honjo T. In Situ Class Switching and Differentiation to IgA-Producing Cells in the Gut Lamina Propria. Nature (2001) 413(6856):639-43. doi: 10.1038/35098100

72. Johansen FE, Pekna M, Norderhaug IN, Haneberg B, Hietala MA, Krajci P, et al. Absence of Epithelial Immunoglobulin A Transport, With Increased Mucosal Leakiness, in Polymeric Immunoglobulin Receptor/Secretory Component-Deficient Mice. J Exp Med (1999) 190(7):915-22. doi: $10.1084 /$ jem.190.7.915

73. Mestecky J, Russell MW. Specific Antibody Activity, Glycan Heterogeneity and Polyreactivity Contribute to the Protective Activity of S-IgA at Mucosal Surfaces. Immunol Lett (2009) 124(2):57-62. doi: 10.1016/j.imlet. 2009.03.013 
74. Li Y, Jin L, Chen T. The Effects of Secretory IgA in the Mucosal Immune System. BioMed Res Int (2020) 2020:2032057. doi: 10.1155/2020/2032057

75. Nakajima A, Vogelzang A, Maruya M, Miyajima M, Murata M, Son A, et al. IgA Regulates the Composition and Metabolic Function of Gut Microbiota by Promoting Symbiosis Between Bacteria. J Exp Med (2018) 215(8):201934. doi: 10.1084/jem.20180427

76. Moor K, Diard M, Sellin ME, Felmy B, Wotzka SY, Toska A, et al. HighAvidity IgA Protects the Intestine by Enchaining Growing Bacteria. Nature (2017) 544(7651):498-502. doi: 10.1038/nature22058

77. Jafarzadeh A, Jamali M, Mahdavi R, Ebrahimi HA, Hajghani H, Khosravimashizi A, et al. Circulating Levels of Interleukin-35 in Patients With Multiple Sclerosis: Evaluation of the Influences of FOXP3 Gene Polymorphism and Treatment Program. J Mol Neurosci (2015) 55(4):8917. doi: $10.1007 / \mathrm{s} 12031-014-0443-\mathrm{z}$

78. Badihian S, Shaygannejad V, Soleimani P, Mirmosayyeb O, Samee Z, Manouchehri N, et al. Decreased Serum Levels of Interleukin-35 Among Multiple Sclerosis Patients May Be Related to Disease Progression. J Biol Regul Homeost Agents (2018) 32(5):1249-53.

79. Kamal A, Hosny M, Abd Elwahab A, Shawki Kamal Y, Shehata HS, Hassan A. FOXP3rs3761548 Gene Variant and Interleukin-35 Serum Levels as Biomarkers in Patients With Multiple Sclerosis. Rev Neurol (Paris) (2021) 177(6):647-54. doi: 10.1016/j.neurol.2020.07.010

80. Correale J, Marrodan M, Carnero Contentti E. Interleukin-35 is a Critical Regulator of Immunity During Helminth Infections Associated With Multiple Sclerosis. Immunology (2021) 164:569-86. doi: 10.1111/imm.13389

81. Probstel AK, Zhou X, Baumann R, Wischnewski S, Kutza M, Rojas OL, et al. Gut Microbiota-Specific IgA(+) B Cells Traffic to the CNS in Active Multiple Sclerosis. Sci Immunol (2020) 5(53):eabc7191. doi: 10.1126/ sciimmunol.abc7191

82. Croxford JL, Feldmann M, Chernajovsky Y, Baker D. Different Therapeutic Outcomes in Experimental Allergic Encephalomyelitis Dependent Upon the Mode of Delivery of IL-10: A Comparison of the Effects of Protein, Adenoviral or Retroviral IL-10 Delivery Into the Central Nervous System. J Immunol (2001) 166(6):4124-30. doi: 10.4049/jimmunol.166.6.4124

83. Cua DJ, Hutchins B, LaFace DM, Stohlman SA, Coffman RL. Central Nervous System Expression of IL-10 Inhibits Autoimmune Encephalomyelitis. J Immunol (2001) 166(1):602-8. doi: 10.4049/jimmunol.166.1.602

84. Dittel BN, Merchant RM, Janeway CA Jr. Evidence for Fas-Dependent and Fas-Independent Mechanisms in the Pathogenesis of Experimental Autoimmune Encephalomyelitis. J Immunol (1999) 162(11):6392-400.

85. Mann MK, Maresz K, Shriver LP, Tan Y, Dittel BN. B Cell Regulation of CD4+CD25+ T Regulatory Cells and IL-10 via B7 is Essential for Recovery From Experimental Autoimmune Encephalomyelitis. J Immunol (2007) 178 (6):3447-56. doi: 10.4049/jimmunol.178.6.3447

86. Ray A, Basu S, Williams CB, Salzman NH, Dittel BN. A Novel IL-10Independent Regulatory Role for B Cells in Suppressing Autoimmunity by Maintenance of Regulatory T Cells via GITR Ligand. J Immunol (2012) 188 (7):3188-98. doi: 10.4049/jimmunol.1103354

87. Zhang AH, Skupsky J, Scott DW. Effect of B-Cell Depletion Using AntiCD20 Therapy on Inhibitory Antibody Formation to Human FVIII in Hemophilia A Mice. Blood (2011) 117(7):2223-6. doi: 10.1182/blood2010-06-293324

88. Khalil MI, Gurski CJ, Dittel LJ, Neu SD, Dittel BN. Discovery and Function of B-Cell IgD Low (BDL) B Cells in Immune Tolerance. J Mol Biol (2021) 433(1):166584. doi: 10.1016/j.jmb.2020.06.023

89. Khalil M, Ray A, Dittel BN. Characterization of the Cell Surface Phenotype and Regulatory Activity of B-Cell IgD Low (BDL) Regulatory B Cells. Methods Mol Biol (2021) 2270:217-31. doi: 10.1007/978-1-0716-1237-8_12

90. Kallies A, Hasbold J, Tarlinton DM, Dietrich W, Corcoran LM, Hodgkin PD, et al. Plasma Cell Ontogeny Defined by Quantitative Changes in Blimp-1 Expression. J Exp Med (2004) 200(8):967-77. doi: 10.1084/jem.20040973

91. Gadalla R, Noamani B, MacLeod BL, Dickson RJ, Guo M, Xu W, et al. Validation of CyTOF Against Flow Cytometry for Immunological Studies and Monitoring of Human Cancer Clinical Trials. Front Oncol (2019) 9:415. doi: $10.3389 /$ fonc. 2019.00415
92. Bonilla DL, Reinin G, Chua E. Full Spectrum Flow Cytometry as a Powerful Technology for Cancer Immunotherapy Research. Front Mol Biosci (2020) 7:612801. doi: 10.3389/fmolb.2020.612801

93. See P, Lum J, Chen J, Ginhoux F. A Single-Cell Sequencing Guide for Immunologists. Front Immunol (2018) 9:2425. doi: 10.3389/fimmu. 2018.02425

94. Zhang C, Yin J, Zheng J, Xiao J, Hu J, Su Y, et al. EZH2 Identifies the Precursors of Human Natural Killer Cells With Trained Immunity. Cancer Biol Med (2021). doi: 10.20892/j.issn.2095-3941.2020.0791

95. Canzar S, Neu KE, Tang Q, Wilson PC, Khan AA. BASIC: BCR Assembly From Single Cells. Bioinformatics (2017) 33(3):425-7. doi: 10.1093/ bioinformatics/btw631

96. Chen X, Yang Z, Chen W, Zhao Y, Farmer A, Tran B, et al. A Multi-Center Cross-Platform Single-Cell RNA Sequencing Reference Dataset. Sci Data (2021) 8(1):39. doi: 10.1038/s41597-021-00809-x

97. Nagaoka K, Shirai M, Taniguchi K, Hosoi A, Sun C, Kobayashi Y, et al. Deep Immunophenotyping at the Single-Cell Level Identifies a Combination of Anti-IL-17 and Checkpoint Blockade as an Effective Treatment in a Preclinical Model of Data-Guided Personalized Immunotherapy. J Immunother Cancer (2020) 8(2):e001358. doi: 10.1136/jitc-2020-001358

98. Kobayashi M, Shelley WC, Seo W, Vemula S, Lin Y, Liu Y, et al. Functional B-1 Progenitor Cells Are Present in the Hematopoietic Stem Cell-Deficient Embryo and Depend on Cbfbeta for Their Development. Proc Natl Acad Sci USA (2014) 111(33):12151-6. doi: 10.1073/pnas.1407370111

99. Saito T, Chiba S, Ichikawa M, Kunisato A, Asai T, Shimizu K, et al. Notch2 Is Preferentially Expressed in Mature B Cells and Indispensable for Marginal Zone B Lineage Development. Immunity (2003) 18(5):675-85. doi: 10.1016/ S1074-7613(03)00111-0

100. Shapiro-Shelef M, Lin KI, McHeyzer-Williams LJ, Liao J, McHeyzerWilliams MG, Calame K. Blimp-1 Is Required for the Formation of Immunoglobulin Secreting Plasma Cells and Pre-Plasma Memory B Cells. Immunity (2003) 19(4):607-20. doi: 10.1016/S1074-7613(03)00267-X

101. Tirosh B, Iwakoshi NN, Glimcher LH, Ploegh HL. XBP-1 Specifically Promotes IgM Synthesis and Secretion, But Is Dispensable for Degradation of Glycoproteins in Primary B Cells. J Exp Med (2005) 202 (4):505-16. doi: 10.1084/jem.20050575

102. Kitano M, Moriyama S, Ando Y, Hikida M, Mori Y, Kurosaki T, et al. Bcl6 Protein Expression Shapes Pre-Germinal Center B Cell Dynamics and Follicular Helper T Cell Heterogeneity. Immunity (2011) 34(6):961-72. doi: 10.1016/j.immuni.2011.03.025

103. Chiu YK, Lin IY, Su ST, Wang KH, Yang SY, Tsai DY, et al. Transcription Factor ABF-1 Suppresses Plasma Cell Differentiation But Facilitates Memory B Cell Formation. J Immunol (2014) 193(5):2207-17. doi: 10.4049/ jimmunol.1400411

104. Inoue T, Shinnakasu R, Kawai C, Ise W, Kawakami E, Sax N, et al. Exit From Germinal Center to Become Quiescent Memory B Cells Depends on Metabolic Reprograming and Provision of a Survival Signal. J Exp Med (2021) 218(1):e20200866. doi: 10.1084/jem.20200866

Conflict of Interest: The authors declare that the research was conducted in the absence of any commercial or financial relationships that could be construed as a potential conflict of interest.

Publisher's Note: All claims expressed in this article are solely those of the authors and do not necessarily represent those of their affiliated organizations, or those of the publisher, the editors and the reviewers. Any product that may be evaluated in this article, or claim that may be made by its manufacturer, is not guaranteed or endorsed by the publisher.

Copyright (C) $2021 \mathrm{Neu}$ and Dittel. This is an open-access article distributed under the terms of the Creative Commons Attribution License (CC BY). The use, distribution or reproduction in other forums is permitted, provided the original author(s) and the copyright owner(s) are credited and that the original publication in this journal is cited, in accordance with accepted academic practice. No use, distribution or reproduction is permitted which does not comply with these terms. 